\title{
The Effect of Bolt Locking Sequences and Anchor Bolt Design on Machine Tool
}

\author{
L. W. Tseng ${ }^{1, *}$, C. Y. Wu ${ }^{1}$, H. Y. Tsai ${ }^{1}$, C. H. Chung ${ }^{1}$, W. L. Huang ${ }^{2}$ \\ ${ }^{1}$ Department of Mechatronics Engineering, National Changhua University of Education, Taiwan \\ ${ }^{2}$ Precision Machinery Research \& Development Center, Taiwan
}

Received August 6, 2020; Revised September 9, 2020; Accepted September 29, 2020

\begin{abstract}
Cite This Paper in the following Citation Styles
(a): [1] L. W. Tseng, C. Y. Wu, H. Y. Tsai, C. H. Chung, W. L. Huang, "The Effect of Bolt Locking Sequences and Anchor Bolt Design on Machine Tool," Universal Journal of Mechanical Engineering, Vol. 8, No. 5, pp. 276 - 286, 2020. DOI: 10.13189/ujme.2020.080505.
\end{abstract}

(b): L. W. Tseng, C. Y. Wu, H. Y. Tsai, C. H. Chung, W. L. Huang (2020). The Effect of Bolt Locking Sequences and Anchor Bolt Design on Machine Tool. Universal Journal of Mechanical Engineering, 8(5), 276 - 286. DOI: 10.13189/ujme.2020.080505.

Copyright $\odot 2020$ by authors, all rights reserved. Authors agree that this article remains permanently open access under the terms of the Creative Commons Attribution License 4.0 International License

\begin{abstract}
Machine tool is an important role in the industry because the mechanical components or products are manufactured by machine tools. The machine tools are assembled by components. The surface between two components is the combined or contact surface. Different bolt locking sequences will affect the combined surface in the machine tool. In this study, the SolidWorks software is used to create the CAD model. The finite element simulation is used the ANSYS software to simulate the influence of bolt locking methods on the combined surface of column structure and guideway and the fillet radius design on the deformation of anchor bolts. From the simulation results, the minimum deformation of the column is observed in the locking sequence from middle to both sides. The stress distribution of the combined surface is slightly difference of three locking methods. The simulation results of the guideway show that the minimum displacement of combined surface is obtained by using locking sequence from outside to the middle. The maximum displacement is obtained locking sequence from right to the left order. From the simulation results of anchor bolt, increasing the fillet radius of anchor bolt decreases the deformation of anchor bolts. The deformation of anchor bolts drastically decreases with increasing the fillet radius from R8 to R60. The simulation models and results provide the reference for the bolt locking sequence and anchor bolt fillet radius design.
\end{abstract}

Keywords Bolt Locking Methods, Column, Machine Tools, Anchor Bolts, Linear Guideway, Fillet Radius Design

\section{Introduction}

The machine tool is the most representation of the precision machine. Every industry such as aerospace, biomedical engineering and automobile need the machine tools to manufacture the components. The machine tools are assembled by many components. The bolts are used to tighten two components. The surface between two components is defined as contact surface or combined surface. Different pretention parameters will affect the combined surface of the machine tools. The appropriate bolt locking methods can not only reduce the deformation and stress of the machine tool during assembly process.

The bolt tightening or preload methods influences the stress and deformation of combined surface and elements. Pawar et al. [1] used the finite element method to simulate the stress on the single lap bolted joint. They found increasing the pretension force will increase the stress and deformation of single lap bolt joint surface. Oskouei et al. [2] investigated the single bolt model of double-lap bolted joint. From the simulation results, the maximum stress is found near the hole of plate. Liu et al [3] use the ABAQUS software to simulate the bolt up process on the assembly structure. Wang and Liu et al. $[4,5]$ investigated the tightening sequence of anchor bolts for large CNC machine tools by using the simulation and experiments. Based on the simulation results, tightening sequence from 
middle to sides could generate uniform deformation of machine bed. Abasolo et al. [6] developed the optimal bolt locking sequence on the wind generator tower bolt joints. They found that the small deformation and stress are in the sequence in cross line methods. Abid et al. [7] used the finite element method to simulate the assembly of a bolted joint in different tightening sequence and design the optimal bolt tightening sequence and number of passes. Nassar et al. [8,9] proposed a new model to investigate the bolt elastic interaction and analyze the various factors on the elastic interaction phenomenon. Sun et al. [10] proposed the mathematic equation to calculate the pretension force or tightening force in the single bolt tightening model. Kim et al. [11] investigated the modeling technique and proposed a single bolt model for simulating the structure with bolt joints in the marine diesel engine. Wang et al. [12,13] used the ABAQUS software to simulate two bolts tightening process in joint member. They used the numerical model and analytic model for calculating the interaction stiffness. Yorgun et al. [14] used the finite element methods to simulate the stress and deformation of a double channel beam to column connection under bending moment and shear. Maggi et al. [15] developed the analytical model to investigate the effect of geometric characteristics on connection behavior in bolted end plate.

Currently, the senior engineering or worker use the torque wrench to tighten the bolts during assembly the components of machine tool. They tighten the bolts in different sequence such as tighten in order, from outside to the middle, from middle to outside based on their experience. They do not have the simulation result to explain why they tighten the bolts in such sequence. As a result, in this research, the horizontal machine tool is design by using the computer-aided design (CAD) software and the finite element method is used to investigate three structures in the machine tools, which are column structure, linear guideway and anchor bolt. Three tightening sequences are based on the senior engineering or worker experience during tightening the components. The studies are investigated by three directions.

(a) the effects of bolt locking sequences or tightening sequence on the stress of column structure and combined surface.

(b) the effect of three bolt tightening sequence on the displacement of linear guideway.

(c) the effect of three different fillet radius design on stress anchor of bolts.

\section{Materials and Methods}

In this study, the three dimension (3D) model is created by using the SolidWorks software. The model are imported in ANSYS workbench with the format IGES for finite element simulation. The finite element method is used to simulate the stress and deformation of the combined or joint surface in the single bolt tightening model. The analysis procedure is listed as follow:

1. Create the 3D CAD model

2. Apply the material properties.

3. Apply the boundary conditions.

4. Apply the force conditions.

5. Apply the Contact conditions

6. Design the model meshing

\subsection{CAD Model of Machine Tool}

The machine tools CAD model is created by using the SolidWorks 2018 software, as shown in Figure 1. The CAD file is imported in ANSYS R19.1 workbench with the format IGES for finite element simulation. In ANSYS software, the analysis system is selected static structural.

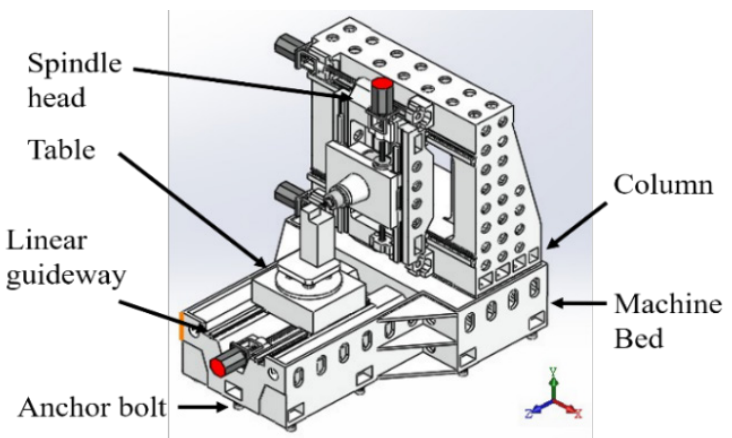

Figure 1. CAD model of machine tools

\subsection{Material Properties}

In the machines tools, almost all the components are used the cast iron. In this study, the material of column structure, machine bed, spindle head, pad of anchor bolt and linear guideway are selected the cast iron. The bolts and nuts are used in the column structure, anchor bolts and linear guideway for tightening two components. The material of bolts and nuts is selected the alloy steel. The material properties of cast iron and alloy steel are shown in Table 1.

Table 1. Material properties of cast iron and alloy steel

\begin{tabular}{|c|c|c|}
\hline Parts & material & E (GPa) \\
\hline Machine tools & cast iron & 120 \\
\hline Bolt and nut & alloy steel & 210 \\
\hline
\end{tabular}

\subsection{Boundary Condition}

In the machine tool, the anchor bolts are fixed in the ground, as shown in the Figure 2(a). Figure 2(b) is the design CAD model of the anchor bolt. The anchor bolt has three components: bolt, nut and pad. The bottom surface of pad is contacted to the ground. As a result, the bottom surface of pad is selected fixed support for the boundary condition, as shown in Figure 2(c). Because there are eleven anchor bolts in this machine tool, total eleven bottom of pad surfaces are selected fixed support (Figure 2(d)). The fixed support in ANSYS software is defined as no displacements in the $\mathrm{x}, \mathrm{y}$ and $\mathrm{z}$ direction. 


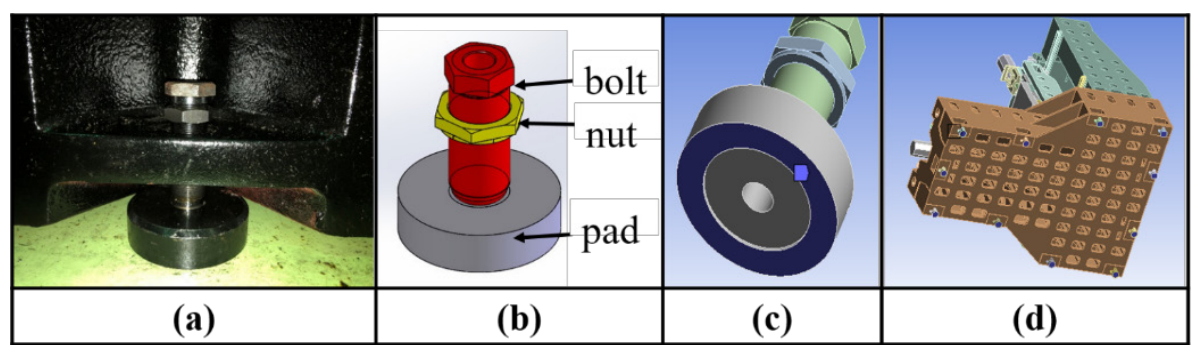

Figure 2. Anchor bolt in machine tool: (a) solid, (b) CAD model, (c) fixed support for boundary condition and (d) fixed support setting of machine tools.

\subsection{Force Condition}

\subsubsection{Gravity force}

The bolts of column structure and anchor bolts are influenced by the weight of machine tool. In the ANSYS software, the gravitational acceleration $(\mathrm{G})$ is set to 9.81 $\mathrm{m} / \mathrm{s}^{2}$ in the -y direction, shown in Figure 3.

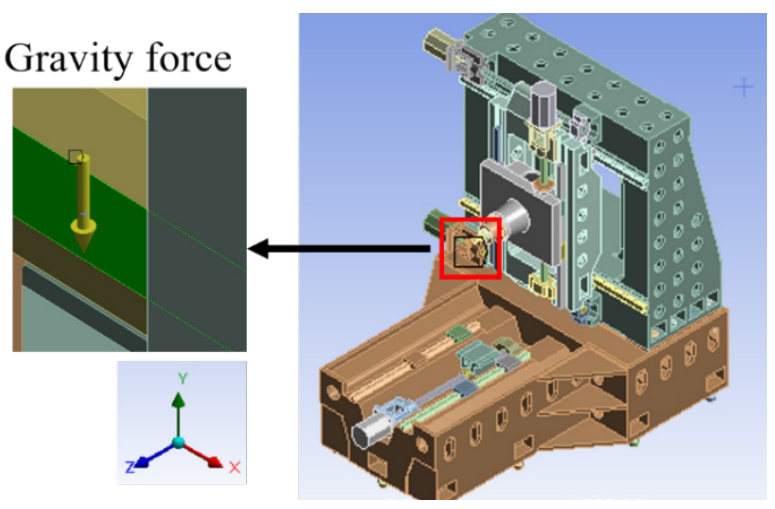

Figure 3. Gravity force setup

\subsubsection{Pretension force}

Tightening the bolts generate the pretension force in the bolts. The pretension force or tightening force can be calculated by equation $1[5,10]$

$$
Q_{P}=\frac{T}{0.2 d}
$$

where:

$$
\begin{aligned}
& \mathrm{Qp}=\text { pretension force }(\mathrm{N}) \\
& \mathrm{T}=\text { torque }(\mathrm{N}-\mathrm{m}) \\
& \mathrm{d}=\text { diameter of bolts }(\mathrm{m})
\end{aligned}
$$

In this study, different diameter of bolts and torque are used to tight the two components in the column, linear guideway and anchor bolts. The bolts which use in the column structure is the M30 (diameter is $30 \mathrm{~mm}$ ) and the torque is $776 \mathrm{~N}-\mathrm{m}$. Using the equation 1 to calculate the pretension force is 129333 N. Figure 4(a), (b) and (c) show the pretension force setting of bolt in column, linear guideway and anchor bolt structure. The calculation of pretension force in column, linear guideway and anchor bolts is summary in Table 2 .

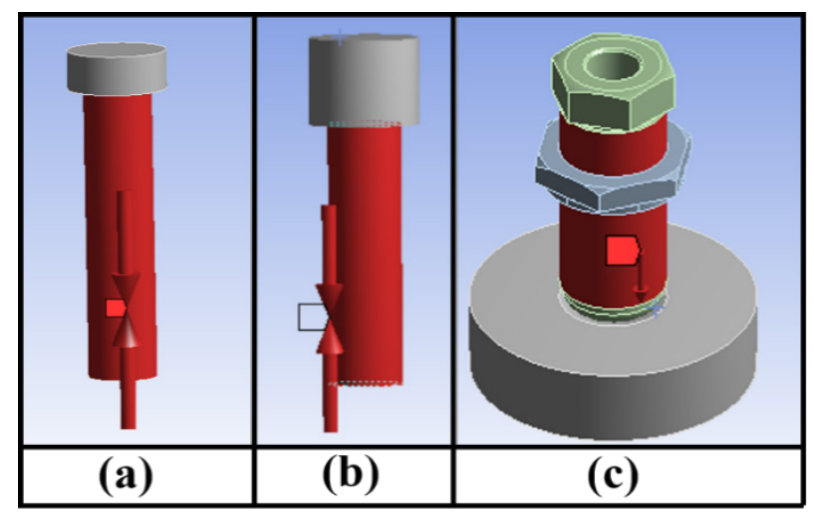

Figure 4. Pretension force setting of bolt: (a) column, (b) linear guideway and (c) anchor bolt.

Table 2. Pretension force column, linear guideway and anchor bolts

\begin{tabular}{|c|c|c|c|}
\hline Parts & $\begin{array}{c}\text { Botls } \\
(\mathrm{mm})\end{array}$ & $\begin{array}{c}\text { Torque } \\
(\mathrm{N}-\mathrm{m})\end{array}$ & $\begin{array}{c}\text { Pretension force } \\
(\mathrm{N})\end{array}$ \\
\hline Column & $\mathrm{M} 30$ & 776 & 129333 \\
\hline Guideway & $\mathrm{M} 12$ & 1200 & 50000 \\
\hline Anchor bolts & $\mathrm{M} 45$ & 1500 & 166666 \\
\hline
\end{tabular}

\subsubsection{Tightening sequence in column structure}

In column structure, there are four bolts in each side of structure. The combined surface between the column structure and machine bed is shown in Figure 5. The numbers from 1 to 8 represent the holes of the combined surface between the column structure and machine bed. The numbers is used to explain the bolt tightening sequence. For example, sequence 1 is first tighten the \#1

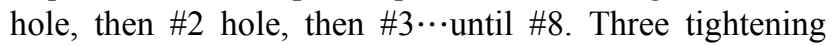
sequences are shown in Table 3. 


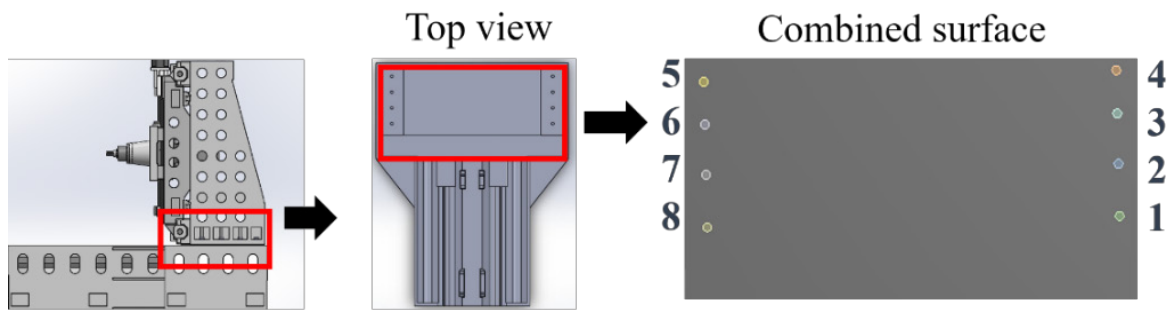

Figure 5. Tightening sequence in combined surface between column structure and machine bed.

Table 3. Tightening sequence of linear column structure

\begin{tabular}{|c|c|}
\hline Number & Sequence \\
\hline Sequence 1 & $1 \rightarrow 2 \rightarrow 3 \rightarrow 4 \rightarrow 5 \rightarrow 6 \rightarrow 7 \rightarrow 8$ \\
\hline Sequence 2 & $1 \rightarrow 8 \rightarrow 5 \rightarrow 4 \rightarrow 3 \rightarrow 6 \rightarrow 7 \rightarrow 2$ \\
\hline Sequence 3 & $2 \rightarrow 6 \rightarrow 7 \rightarrow 3 \rightarrow 8 \rightarrow 4 \rightarrow 1 \rightarrow 5$ \\
\hline
\end{tabular}

\subsubsection{Tightening sequence in linear guideway}

In this machine tool, twelve bolts are used to tighten for each side of linear guideway, as shown in Figure 6(a). Figure 5 (b) is the top view of linear guideway. The numbers from 1 to 12 represent the holes of the combined surface between the top and bottom guideway structure from left to right. The purpose of number is the same as number in the column structure. There are total three locking sequences. Sequence 1 is from left to the right, sequence 2 is from outside to the middle and sequence 3 is from middle to outside. Three tightening sequences are shown in Table 4.

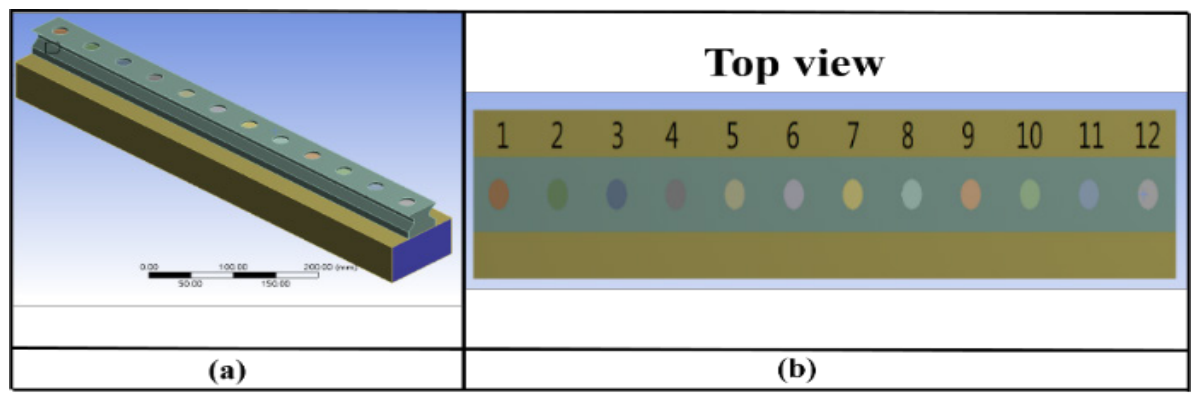

Figure 6. Linear guideway: (a) CAD model and (b) top view.

Table 4. Tightening sequence of linear guideway

\begin{tabular}{|c|c|}
\hline Number & Sequence \\
\hline Sequence 1 & $1 \rightarrow 2 \rightarrow 3 \rightarrow 4 \rightarrow 5 \rightarrow 6 \rightarrow 7 \rightarrow 8 \rightarrow 9 \rightarrow 10 \rightarrow 11 \rightarrow 12$ \\
\hline Sequence 2 & $1 \rightarrow 12 \rightarrow 2 \rightarrow 11 \rightarrow 3 \rightarrow 10 \rightarrow 4 \rightarrow 9 \rightarrow 5 \rightarrow 8 \rightarrow 6 \rightarrow 7$ \\
\hline Sequence 3 & $6 \rightarrow 7 \rightarrow 5 \rightarrow 8 \rightarrow 4 \rightarrow 9 \rightarrow 3 \rightarrow 10 \rightarrow 2 \rightarrow 11 \rightarrow 1 \rightarrow 12$ \\
\hline
\end{tabular}

\subsection{Contact Condition}

\subsubsection{Contact condition in column structure}

In column structure, there are total three contain regions: (a) the surface between the bottom of nut and column, (b) the surface between bolts and holes and (c) the surface between column and machine bed. The contact conditions for (a) and (c) are friction. The coefficient of friction is 0.18 . The contact condition for (b) is bond. The contact conditions are shown in the Figure 7(a), (b), (c), (d) and Table 5.

Table 5. Contact condition of column structure

\begin{tabular}{|c|c|}
\hline Contact surface & Conditions \\
\hline Bolt nut and column & Frictional $(\mu \mathrm{s}=0.18)$ \\
\hline Bolt and hole of machine bed & bond \\
\hline Column and machine bed & Frictional $(\mu \mathrm{s}=0.18)$ \\
\hline
\end{tabular}




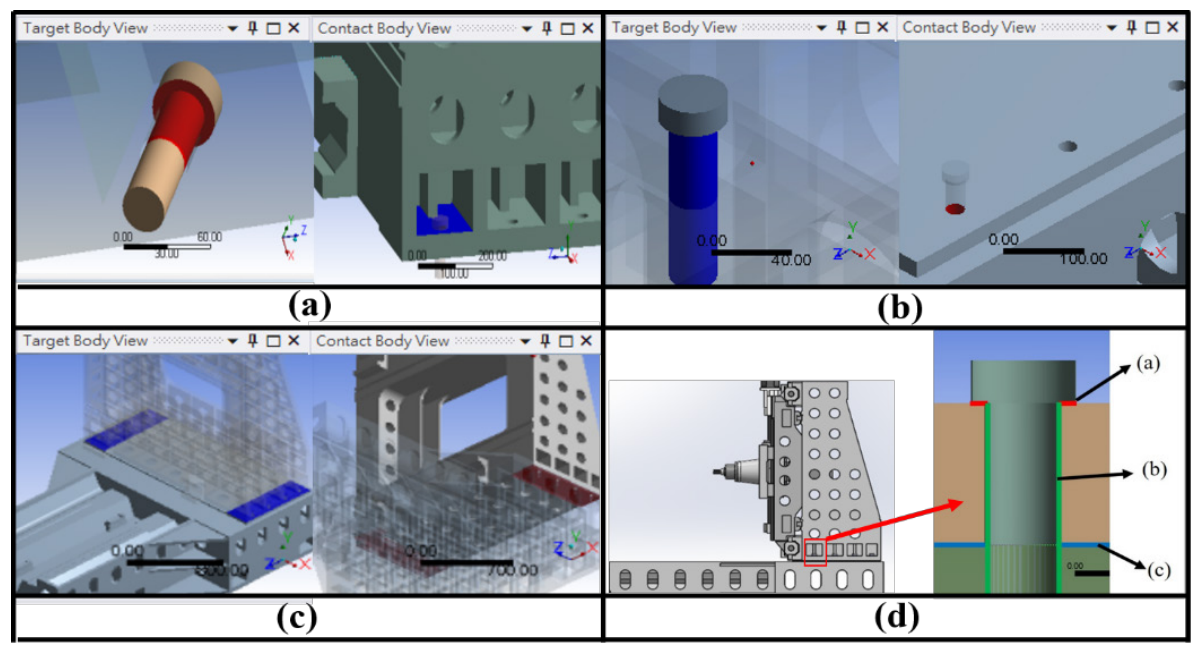

Figure 7. Contact conditions in column: (a) the contact surface between the bottom of nut and column, (b) the contact surface between the bolts and holes, (c) the contact surface between the column structure and machine bed and (d) the single bolt section view from the column structure to show the location of contact surfaces (a), (b) and (c).

\subsubsection{Contact condition in linear guideway}

There are three contact surfaces in linear guideway: (a) contact surfaces between bottom of nut and linear guideway, (b) contact surfaces between linear guideway and base and (c) contact surfaces between bolts and holes. The contact condition for (a) and (b) are frictional. The coefficient of friction is 0.18 . The contact condition for (c) is bond. The contact conditions are shown in the Figure 8(a), (b), (c) and Table 6.

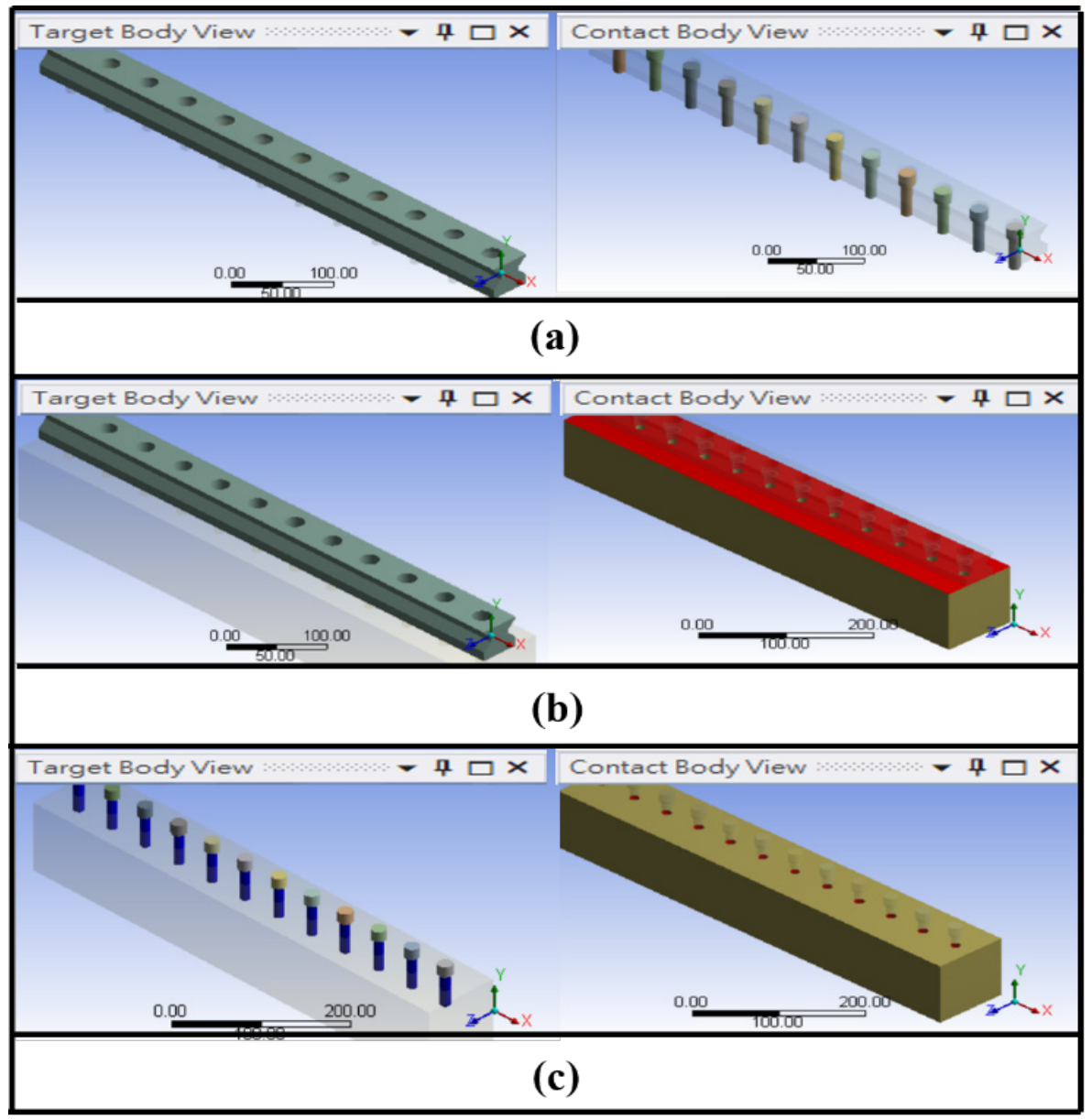

Figure 8. Contact condition in linear guideway: (a) contact surfaces between bottom of nut and linear guideway, (b) contact surfaces between linear guideway and base and (c) contact surfaces between bolts and holes. 
Table 6. Contact condition of linear guideway

\begin{tabular}{|c|c|}
\hline Contact surface & Conditions \\
\hline Bottom surface of nut and guideway & Frictional $(\mu \mathrm{s}=0.18)$ \\
\hline Linear guideway and base & Bond \\
\hline Bolts and holes of guideway & Frictional $(\mu \mathrm{s}=0.18)$ \\
\hline
\end{tabular}

\subsubsection{Contact condition in anchor bolts}

In anchor bolts, two contact surface: (a) the surface between bolt and pad and (b) the surface between bolt and nut. The contact conditions for (a) is frictional. The coefficient of friction is 0.18 . The contact conditions for (b) is bond. The contact conditions are shown in the Figure 9(a), (b) and Table 7.

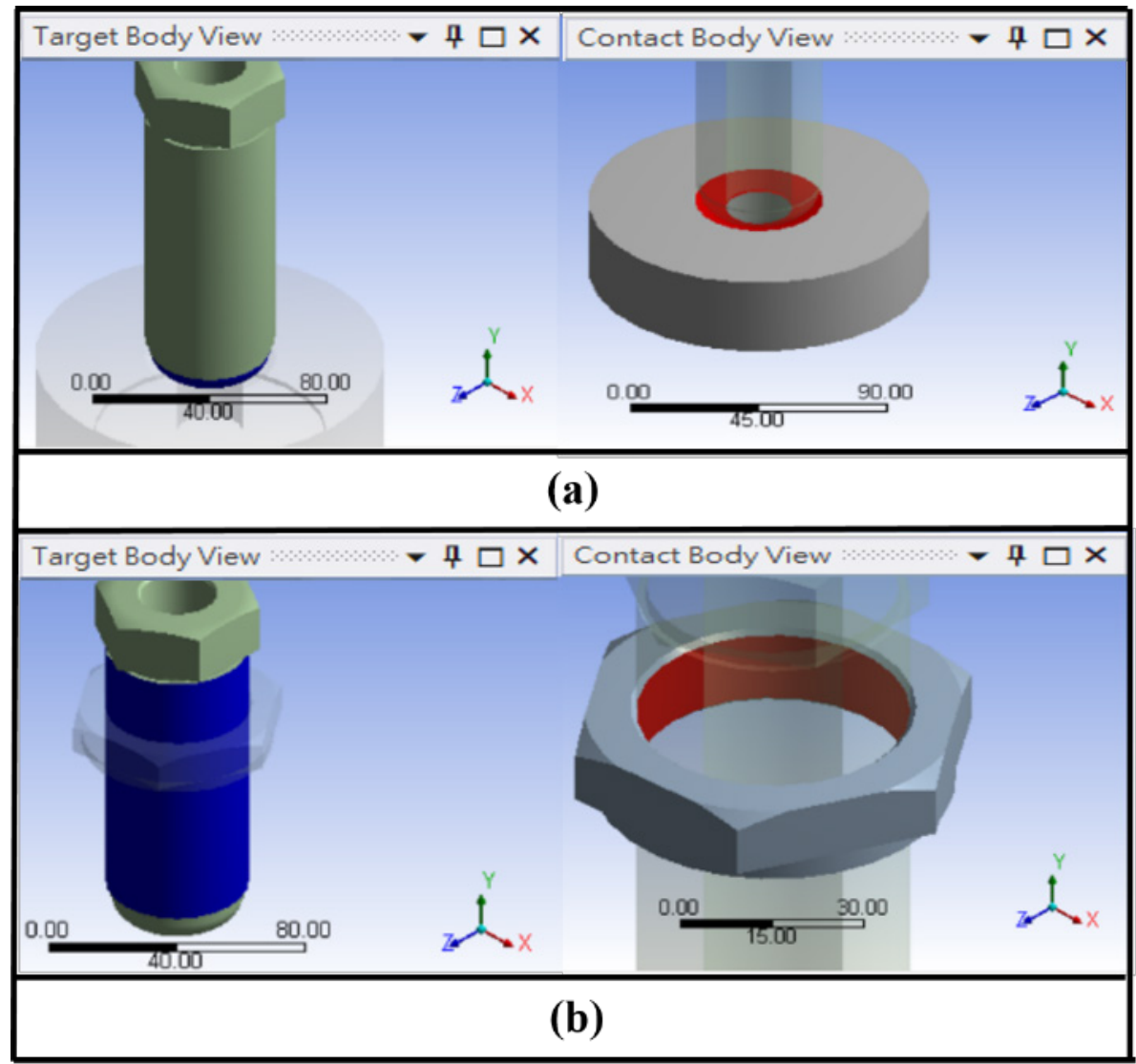

Figure 9. Contact conditions in linear guideway: (a) the surface between bolt and pad and (b) the surface between bolt and nut.

Table 7. Contact conditions of anchor bolt

\begin{tabular}{|c|c|}
\hline Contact surface & Conditions \\
\hline Bolt and pad & Frictional $(\mu \mathrm{s}=0.18)$ \\
\hline Bolt and nut & Bond \\
\hline
\end{tabular}




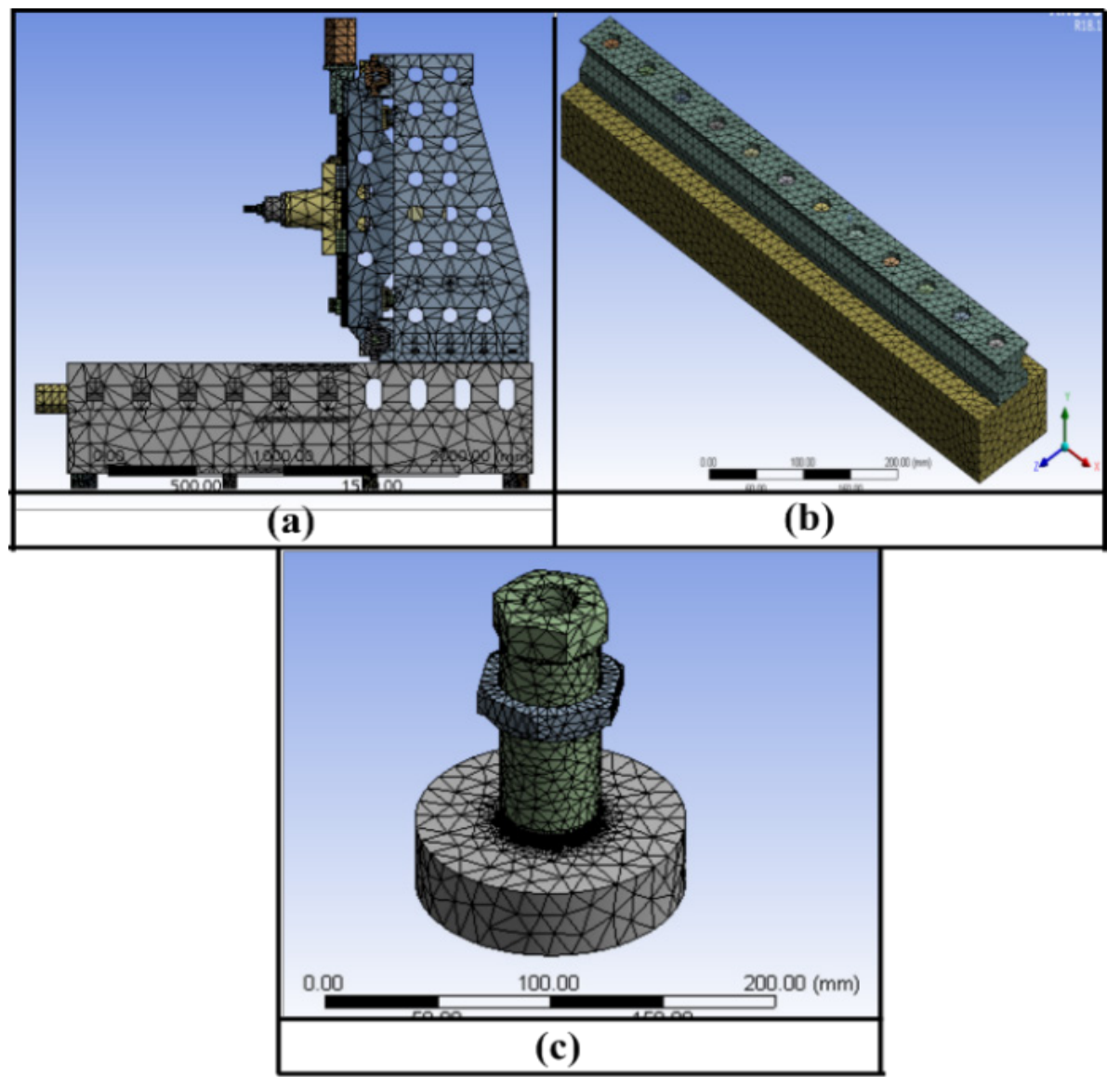

Figure 10. Meshing condition of machine tool: (a) machine tools, (b) linear guideway and (c) anchor bolt.

\subsection{Meshing Condition}

The meshing condition of machine tool is used generate meshing. The machine tool (column structure, linear guideway and anchor bolt) after the meshing is shown in Figure 10(a), (b) and (c).

\section{Results and Discussion}

\subsection{The Effect of Tightening Sequence on Column}

3.1.1. von-Mises stress on column structure

Figure 11(a), (b) and (c) show the von-Mises stress of column structure in horizontal machine tool with three different tightening sequences. The von-Mises stress of three tightening sequence is summary in Figure 11(d). From the simulation results, the maximum stress is obtained in the sequence 3 (tight from middle to outside). The minimum stress is observed in the sequence 2 (tight from outside to middle). 


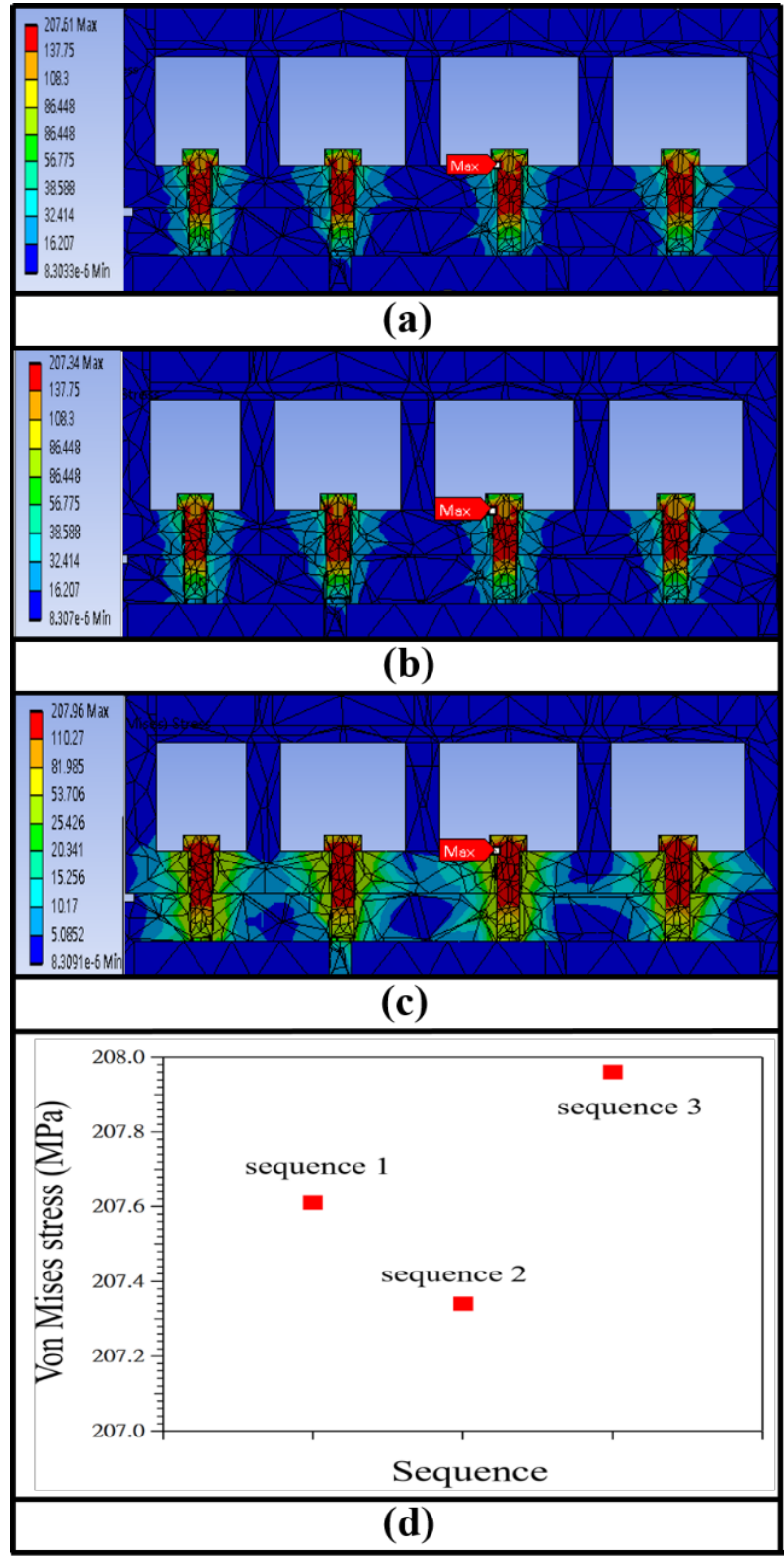

Figure 11. The von-Mises stress of column structure with three different tightening sequence. (a) sequence 1, (b) sequence 2 and (c) sequence 3. (d) Comparison of von Mises stress in three sequences.

\subsection{2. von-Mises stress on combined surface}

Figure 1221(a), (b) and (c) show the von-Mises stress of combined surface between the column structure and base with three different tightening sequences. The von-Mises stress of three tightening sequence is summary in Figure 12(d). From the simulation results, the minimum stress is obtained in the sequence 2 (tight from outside to middle). The von-Mises stress in the sequence 2 and 3 is almost the same.

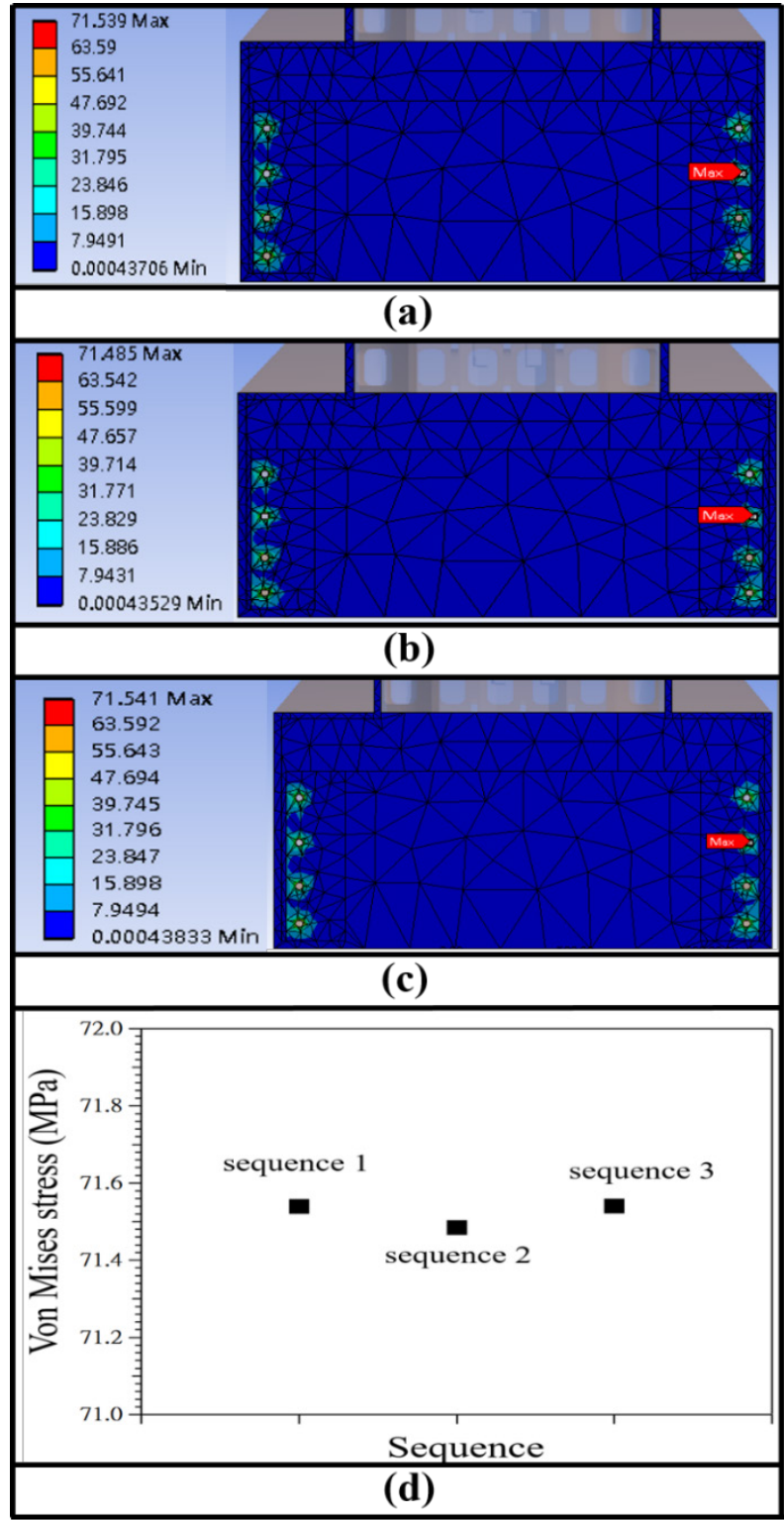

Figure 12. The von-Mises stress of combined surface with three different tightening sequence. (a) sequence 1 , (b) sequence 2 and (c) sequence 3. (d) Comparison of von Mises stress in three sequences.

\subsection{The Effect of Tightening Sequence on Linear Guideway}

\subsubsection{Total deformation on combined surface}

Figure 13(a), (b) and (c) show the total deformation $(\mathrm{mm})$ of linear guideway of horizontal machine tool with three different tightening sequences. The total deformation $(\mu \mathrm{m})$ of three tightening sequence is summary in Figure 13(d). From the results, the minimum deformation is obtained in the sequence 2 (tight from outside to the middle). 


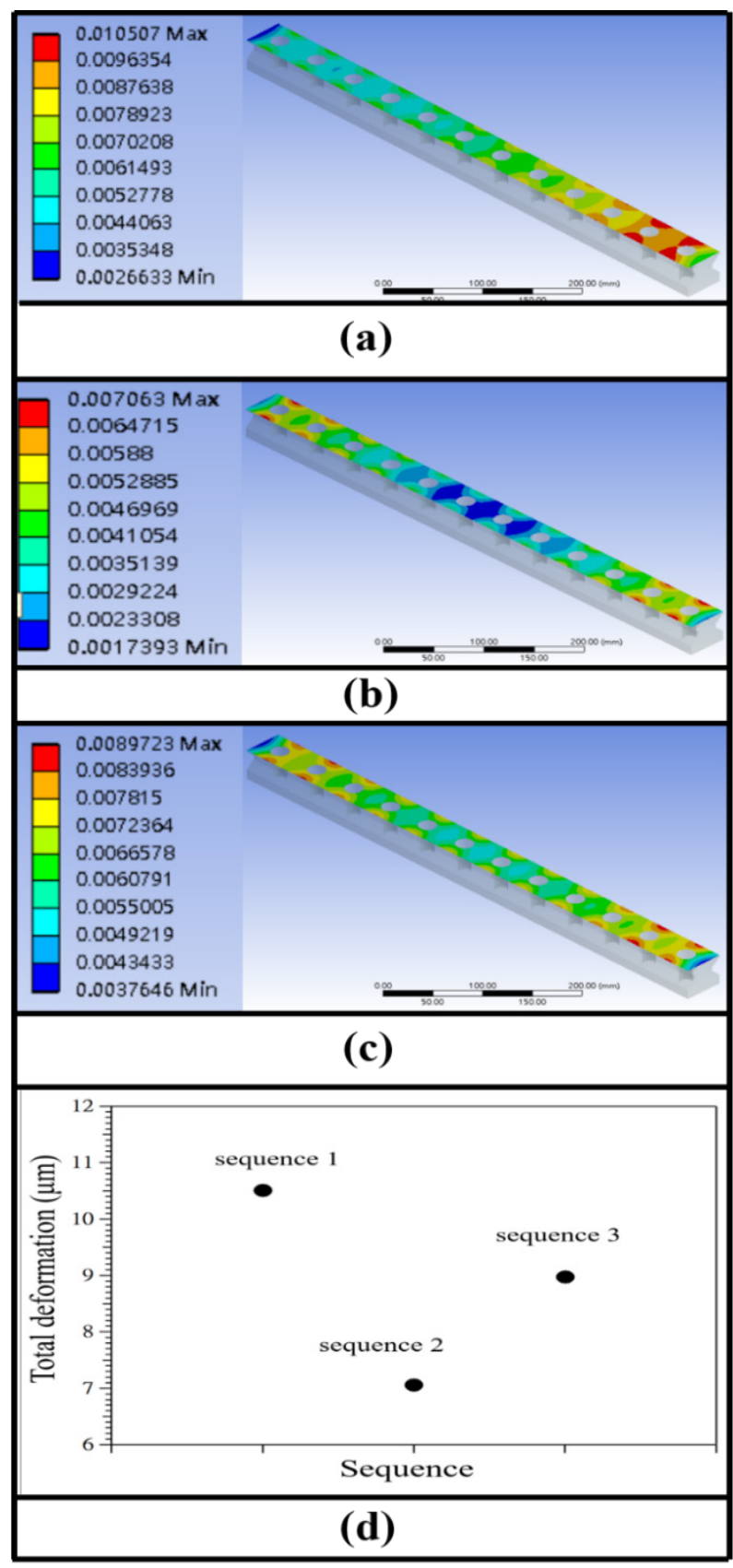

Figure 13. The total deformation of linear guideway with three different tightening sequence. (a) sequence 1 , (b) sequence 2 and (c) sequence 3. (d) Comparison of total deformation in three sequences.

\subsubsection{Total deformation on central surface}

Figure 14(a), (b) and (c) show the total deformation $(\mathrm{mm})$ of central surface of linear guideway with three different tightening sequences. The total deformation $(\mu \mathrm{m})$ of three tightening sequence is summary in Figure 14(d). From the results, the maximum deformation is in sequence 1 (tight in order) and the minimum deformation is in the sequence 2 (tight from outside to the middle).

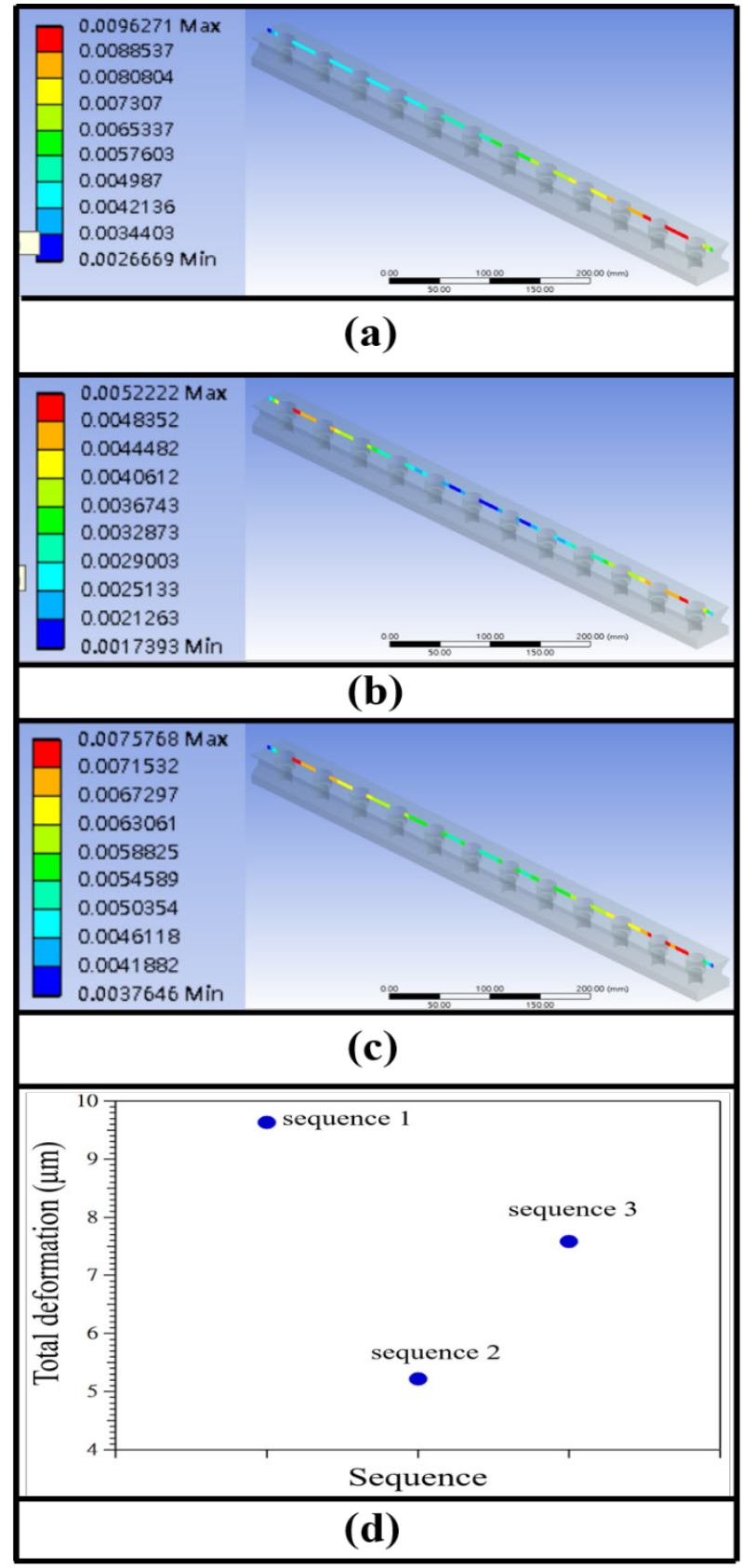

Figure 14. The total deformation of linear guideway with three different tightening sequence. (a) sequence 1, (b) sequence 2 and (c) sequence 3. (d) Comparison of total deformation in three sequences.

\subsection{The Effect of Radius Design on Anchor Bolt}

\subsubsection{Total deformation on anchor bolt}

Figure 15(a), (b) and (c) show the total deformation $(\mathrm{mm})$ of anchor bolt with three different radius (R8, R30, $\mathrm{R} 60)$ design. The total deformation $(\mu \mathrm{m})$ of three radius is summary in Figure 15(d). From the results, the total deformation decreases with increasing the $\mathrm{R}$ angle. 


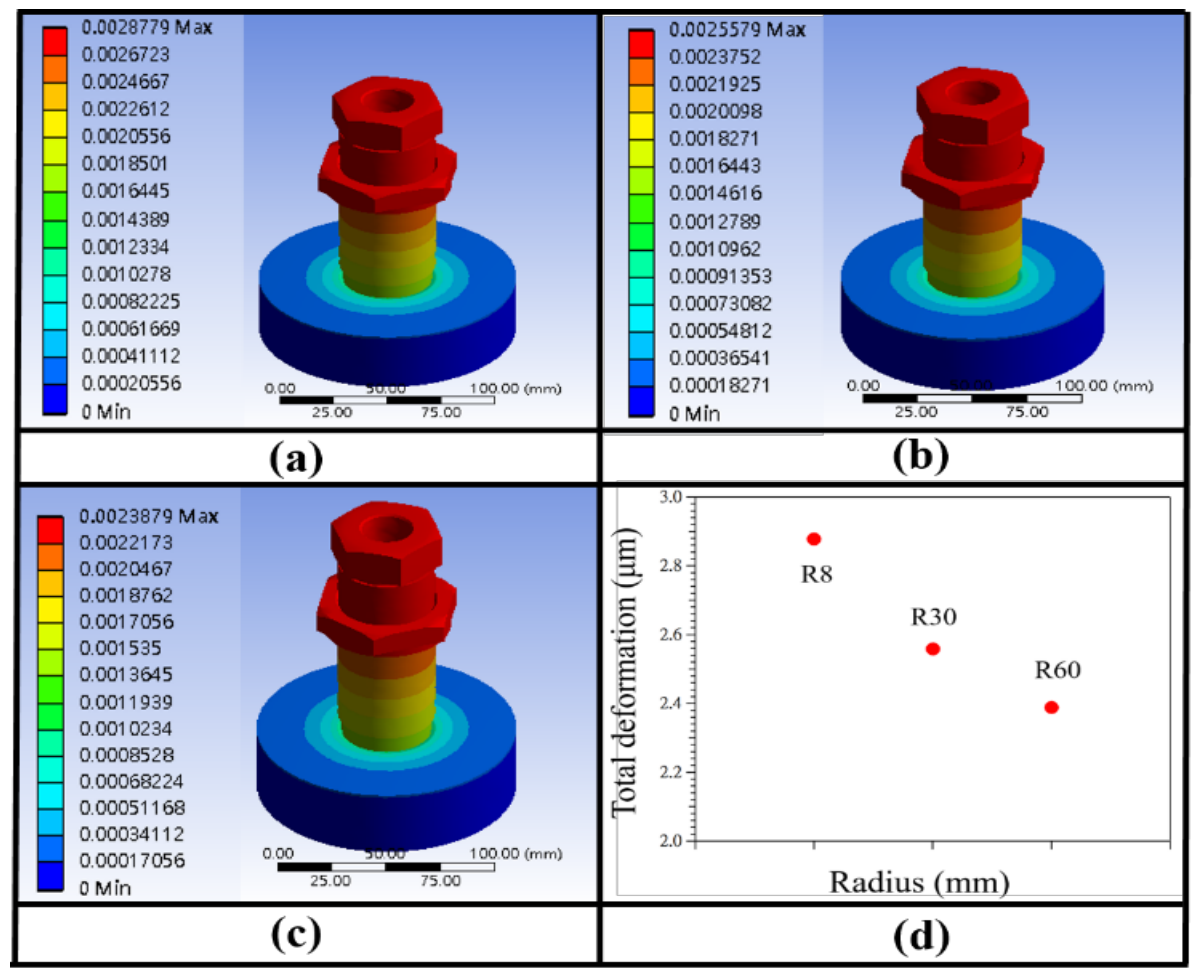

Figure 15. The total deformation of anchor bolt with three different fillet radius. (a) R8, (b) R30 and (c) R60. (d) Comparison of total deformation in three fillet radius

\subsubsection{Total deformation on pad}

Figure 16(a), (b) and (c) show the total deformation ( $\mathrm{mm}$ ) of pad with three different fillet radius (R8, R30 and R60) design. Figure 16(d) shows the comparison of total deformation $(\mu \mathrm{m})$ in three fillet. From the results, the pad of total deformation decreases with increasing the $\mathrm{R}$ radius.

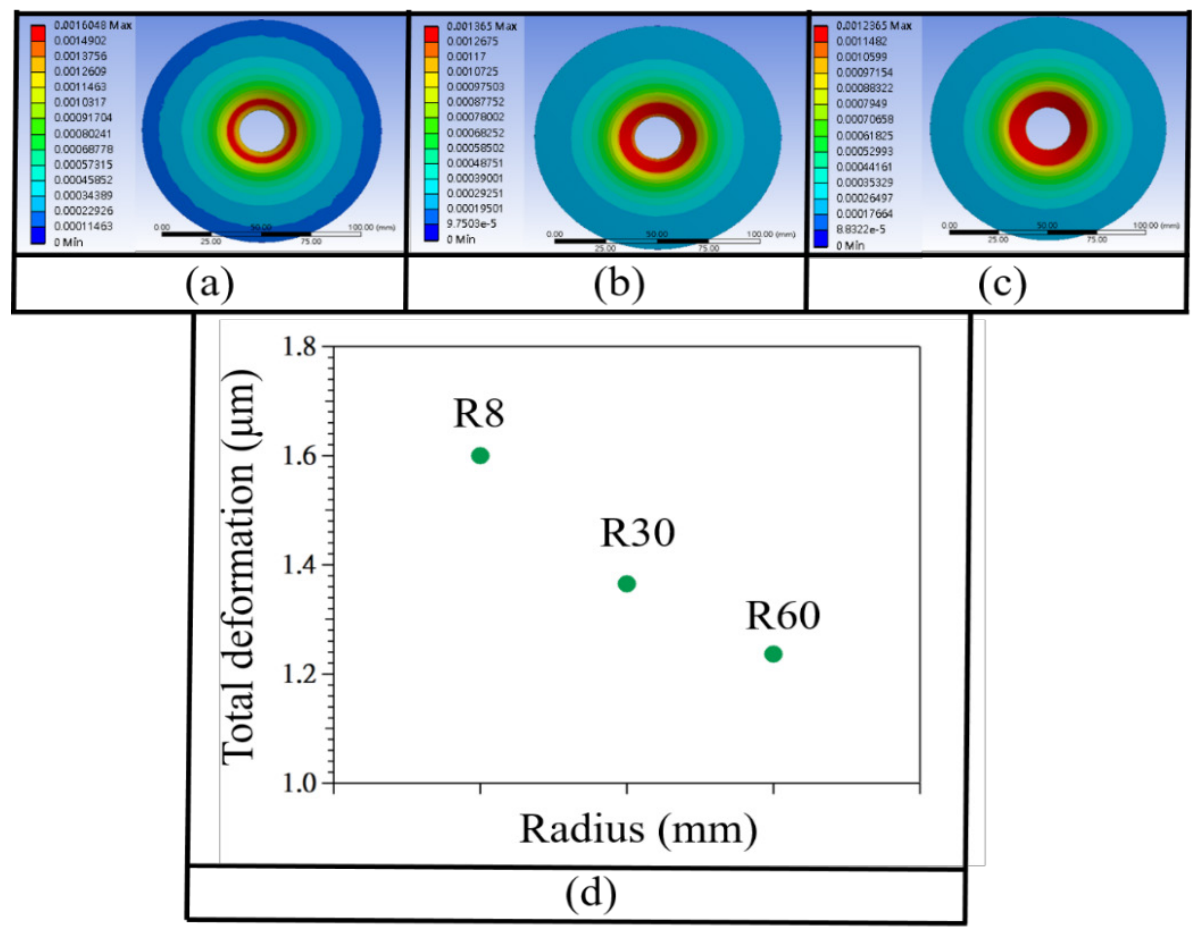

Figure 16. The total deformation of pad with three different fillet radius. (a) R8, (b) R30 and (c) R60. (d) Comparison of total deformation in three fillet radius. 


\section{Conclusions}

In summary, the effect of bolts locking sequences on column structure and linear guideway and anchor bolt fillet radius in machine tool was investigated for the first time under finite element method. Major findings can be summarized as follows:

(a) For the column structure, the maximum stress is obtained in the sequence 3 (tight from middle to outside and the minimum stress is observed in the sequence 2 (tight from outside to middle).

(b) The simulation results of guideway, the minimum displacement of combined surface is obtained by using locking sequence from outside to the middle. The maximum displacement is observed in the locking sequence in order.

(c) Total deformation of anchor bolts and pads drastically decrease with increasing the fillet radius from $\mathrm{R} 8$ to $\mathrm{R} 60$

\section{Acknowledgments}

The authors gratefully acknowledge that Precision Machinery Research \& Development Center supported for this work. Project number is 108TR04. Simulation and technical experience of machine tools from Dr. Wei-Lun Huang are gratefully acknowledged.

\section{REFERENCES}

[1] J.S. Pawar, M. Chouksey, K. Tripathi. Modeling and stress analysis of single lap bolted joint, Universal Journal of Mechanical Engineering, Vol.3, No.1, 21-26, 2015.

[2] R.H. Oskouei, M. Keikhosravy, C. Soutis. Estimating clamping pressure distribution and stiffness in aircraft bolted joints by finite-element analysis, Proc. IMechE, Vol. 223 , 863-871, 2009.

[3] K. Liu, W. Liu. Analysis of bolt preload based on ABAQUS, Machinery manufacturing and automation, Vol.2, 105-107, 2011.
[4] Y.Q. Wang, J.K. Wu, H.B. Liu. Modeling and numerical analysis of multi-bolt elastic interaction with bolt stress relaxation, Journal of Mechanical Engineering Science, Vol. 230, 2579-2582, 2016

[5] H. Liu, J. Wu, K. Liu, K. Kung K, Q. Liu, Z. Liu, Y. Wang. Pretightening sequence planning of anchor bolts based on structure uniform deformation for large CNC machine tools, International Journal of Machine Tools and Manufacture, Vol. 136, 1-18, 2019.

[6] M. Abasolo, J. Aguirrebeitia, R. Aviles. Methodology for the optimization of bolting sequences for wind generator flanges, Journal of Pressure Vessel Technology, Vol 6, 136-149, 2014.

[7] M. Abid, S. Hussain. Relaxation behaviour of gasketed joints during assembly using finite element analysis, Sadhana Vol. 35, 31-43, 2010

[8] S.A. Nassar, X. Yang. Novel formulation of bolt elastic interaction in gasketed joints, J Pressure Vessel Technol Vol. 05, 131-135, 2009.

[9] S.A. Nassar, A. Abboud. An improved stiffness model for bolted joints, J. Mech. Vol. 131 25-29, 2009.

[10] X. Sun, Y. Mai. Analysis of stress under bolt pretension, An improved stiffness model for bolted joints, Electronic Science and Technique, Vol. 2, 65-67, 2017.

[11] J. Kim, J.C. Yoon, B.S. Kang. Finite element analysis and modeling of structure with bolted joints, Applied Mathematical Modelling, Vol. 31, 895-911, 2007.

[12] Y. Wang, J. Wu, H. Liu, S. Xu. Modeling and numerical analysis of multi-bolt elastic interaction with bolt stress relaxation, Proceedings of the Institution of Mechancial Engineering Science, Part C: Journal of Mechanical Engineering Science, Vol. 230, 2579-2587, 2015.

[13] Y. Wang, J.K. Wu, H. Liu, K. Kuang, X.W. Cui, L.S. Han. Analysis of elastic interaction stiffness and its effect on bolt preloading, International Journal of Mechanical Sciences, Vol. 130, 307-314, 2017.

[14] C. Yorgun, S. Dalcl, G.A. Altay. Finite element modeling of bolted steel connections designed by double channel, Computers \& Structures, Vol. 82, 2563-2571, 2004.

[15] Y.I. Maggi, R.M. Conclves, R.T. Leon, L.F.L. Ribeiro. Parametric analysis of steel bolted end plate connections using finite element modeling, Journal of Constructional Steel Research, Vol. 61, 689-708, 2005. 